\section{Birds of Ecuador. ${ }^{1}$}

THIS is a companion volume to the "Distribution of Bird-Life in Colombia," forming vol. 36, 1917, of the Bulletin of the American Museum. It differs from many other valuable ornithological books in the fact that at least one-third of it is most interesting reading, and not for specialists in ornithology alone. The introductory chapters, after giving a review of the history of Ecuadorean ornithology, and describing the work done in Ecuador by the American Museum's expeditions, partially under the leadership of the author himself, describes clearly and vividly the general physiography of the country, the distribution of forests, the climatic conditions, and chiefly the life-zones. The author admits four life-zones: the tropical, the subtropical, the temperate, and the Paramo zone, which is the treeless region above 11,000 feet to the snow line.

While the avifauna of the subtropical zone must have derived from the tropical, and that of the temperate from the subtropical one, that of the Paramo, the youngest Andean zone, has acquired its bird-life comparatively recently, not from the neighbouring temperate zone of the Ecuadorean Andes, but very largely from its sea-level equivalent in Patagonia. This is fully explained by numerous examples. In comparing the various regions, numbers of genera are often used; this is not very useful, however, as the limits of genera are so differently defined by various ornithologists, the number of genera generally being greater in American works than in European, with one or two exceptions. It would be better if comparative lists of faunal regions were only given in species and subspecies.

Both books of Dr. Chapman show how wonderfully rich in species the highlands of the Andes are, in comparison with, for example, the elevated portions of Africa ; thus, while on Ruwenzori only 95 'zonal' birds, as the author calls them, are known, not less than 412 are recorded from Ecuador, of which about 300 could be found within an area no larger than that occupied by Mt. Ruwenzori. This is doubtless due to the much larger extent of the highlands of the Andes as well as to their much greater height, but also, one may add, to the fact that altogether South America-even the lowlands-is richer in species than Africa. 1508 species and subspecies are included in the list of the birds of Ecuador, a larger number than has before been recorded from an area of similar size. Only 151 forms are treated trinomially as subspecies. The reason for this is that a number of forms have been admitted as species, because it is not known that they intergrade with others. This is still often done in America, but the known existence of intergradations is due to the material available in collections, and it is impossible to say if intergradations occur in the case of rarer birds, of which only a few skins are known. The method of many modern European ornithologists, who regard as subspecies all forms agreeing in the essential characters and only differing in shades of colour, size, or other details, if they strictly represent each other geographically, seems to be more natural.

Dr. Chapman is to be congratulated on his book, which is adorned by maps, photographs of scenery, and by excellent coloured plates of birds, and it is to be hoped that a volume on the birds of Peru may follow before long, so as to give us a still fuller knowledge of the birds of western South America.

${ }^{1}$ Bulletin of the American Museum of Natural History. Vol. 55, 1926 : The Distribution of Bird-Life in Ecuador; a Contribution to a Study of the Origin of Andean Bird-Life. By Frank M. Chapman. Pp. xivt $784+30$ plates. (New York: American Museum of Natural History, 1926.)

No. 2991, VoL. 119]

\section{University and Educational Intelligence.}

CAMRRIDGE.- The following have been appointed as the Council of the School of the Physical Sciences: Mr. A. Berry, Mr. Cameron, Prof. Eddington, Mr. R. H. Fowler, Prof. Hutchinson, Prof. Inglis, Dr. H. Jeffreys, Mr. Landon, Sir Joseph Larmor, Mr. Lees, Mr. McCombie, Prof. Newall, Sir William Pope, Sir Ernest Rutherford, Prof. G. I. Taylor, Mr. L. B. Turner.

Dr. A. C. Haddon has been elected a member of the governing body of the International Institute of African Languages and Cultures. Dr. R. R. Marrett will give the Frazer lecture on Mar. 2 on the subject,

The Diffusion of Culture."

The General Board of Studies has recommended to the University that the readership in geography, about to become vacant by the resignation of $\mathrm{Mr}$. Lake, should be continued.

Honorary degrees are proposed for BrigadierGeneral E. W. Costello, V.C., officer in command of the University contingent of the Officers' Training Corps, and for Colonel T. C. Hodson, reader in ethnology.

Three Davison scholars will be elected next term for a year's study at Harvard, Yale, and Princeton Universities. Scholars are chosen from undergraduates or bachelors of arts in residence.

THE Faraday House Journal for the Lent term shows that there are 83 students in their first year in the college, 51 in their second year, which is spent in mechanical engineering works, 74 in their third year, spent in college, and 71 in their fourth year, spent in electrical engineering works. The names of 45 old students who have obtained appointments since the issue of the Michaelmas number of the journal are given, with the titles of the posts obtained. There are five short scientific articles by staff and old students, amongst them one by the Principal, Dr. A. Russell, showing that the recent experiments which appear to indicate that an electric spark can pass between electrodes near together when the difference of potential between them is less than 350 volts, are probably vitiated by the electrostatic attraction between the electrodes having pulled them together. There are several scholarships and exhibitions offered by the college to be competed for in April next.

THE prefatory note to a pamphlet published by the Universities Bureau of the British Empire (50 Russell Square. London, W.C.I), entitled "Professional Schools, Post-Graduation Courses, Specialist Studies, in the Universities and University Colleges of Great Britain and Ireland, 1926-27," clearly describes its purpose: "Of their [the universities] several fields of study the greater part is common ground, yet each of them has its special plots which it cultivates. . . The statements which follow indicate the respects in which the universities, individually, specialise, i.e. undertake work which is not common to them all." That the pamphlet accomplishes what it promises can best be shown if it be imagined that half-a-dozen students, unacquainted with the "special plots" of universities, desired, respectively, to attend lectures in oceanography, constitutional experiments in the Irish Free State, problems of bi-lingualism, tuberculous diseases, technical chemistry, the leather industry. Twenty minutes' study of this pamphlet would save them hours of hunting through bulky prospectuses and calendars, and would save much preliminary correspondence with registrars. 